\title{
MEIO-AMBIENTE E SUSTENTABILIDADE LOGÍSTICA: HUMANIZAÇÃO DA PRODUÇÃO ATRAVÉS DE ARRANJOS PRODUTIVOS LOCAIS NO ESTADO DE SÃO PAULO
}

\author{
ENVIRONMENT AND LOGISTIC SUSTAINTABILITY: PRODUCTIVE \\ HUMANIZATION THROUGH CLUSTERS IN THE STATE OF SAO PAULO
}

\author{
Marly Cavalcanti ${ }^{1}$; Osvaldo Elias Farah ${ }^{2}$ \\ ${ }^{1}$ Universidade - Centro Paula Souza - São Paulo - Brasil cavalcanti.marly@gmail.com \\ ${ }^{2}$ Universidade - UNIMEP - São Paulo - Brasil oefarah@gmail.com
}

\begin{abstract}
Resumo
Este artigo considera a evolução da sustentabilidade logística em diferentes momentos históricos de municípios do Estado de São Paulo, entendendo-a como competência estratégica essencial que permite a humanização da produção, através de arranjos produtivos locais e compartilhamento de informações entre empresas, os quais tem efeito multiplicador para gestão de recursos intangíveis como o conhecimento e o desenvolvimento gerencial. Examina-se, ainda, o grau de desenvolvimento municipal ao longo de três décadas sucessivas, anos 70, anos 80 e anos 90, apontando a formação de quatro grandes pólos logísticos, a partir de aglomerados de empresas e instituições locais colaborativas de trabalho, com inserção de mão-de-obra. $O$ artigo também aponta o reconhecimento destes pólos e seu mapeamento como contribuição significativa para medir os impactos das operações no meio ambiente físico e humano das áreas produtivas. A metodologia utilizada foi a análise fatorial a qual indicou diversos fatores de sustentabilidade logística no território do Estado.
\end{abstract}

Palavras-chave: meio ambiente; pólos regionais; sustentabilidade.

\section{Introdução}

Uma das estratégias mais eficazes para que empresas locais possam competir com grandes empresas de atuação nacional ou global é focar o negócio no atendimento de segmentos específicos do mercado regional em que elas estarão localizadas (Bassi, 2000) ${ }^{1}$. Podemos, portanto, analisar municípios a partir de sua inserção em uma matriz de competitividade local, em que um dos eixos refere-se aos fatores críticos de sucesso ou fracasso de estratégias locais, e o eixo horizontal verifica tendências destes mesmos fatores críticos ao longo do tempo.

1 A matriz de competitividade leva-nos a considerar a evolução das cidades do Estado de São Paulo ao longo de quase 30 anos, bem como a examinar fatores críticos de desenvolvimento local. Bassi (2000). 
Villassante (2002) ressalta que o problema não está nos valores, nem nos objetivos, nem nos sujeitos sociais, mas em deixar passar a análise de relações entre eles e as intrincadas redes sociais. A mudança de valores tem de acompanhar-se de informes muito claros que verifiquem, na prática, como as coisas estão mudando. É o re-equilíbrio sustentável através de indicadores que substituam o PIB, tratando-se de abandonar o critério único do crescimento econômico, mudando-o para uma programação de transição estratégica econômica e desenvolvimento sustentável. Novas redes e uma nova visão devem ser procuradas, aglutinando pólos emergentes, e empreendedorismo.

As economias externas locais estão no cerne da discussão sobre clusters porque são elas que determinam a própria existência da aglomeração ao proporcionarem custos reduzidos para as empresas aglomeradas. São também chamadas de economias externas Marchallianas, e incluem vantagens decorrentes (1) da existência de um denso mercado local de mão-de-obra especializada; (2) das facilidades de acesso a fornecedores de matérias primas, componentes, insumos e serviços especializados e, muitas vezes, também de máquinas e equipamentos e (3) da maior disseminação local de conhecimentos especializados que permitem rápidos processos de aprendizado, criatividade, inovação, e humanização da produção.

Entretanto, soma-se a isto a necessária forma de organização e coordenação das empresas regionais em atividades similares ou relacionadas, o que influi na formação e evolução dos APLs. A ela podem somar-se economias externas de regiões, resultantes de ações conjuntas e deliberadas das empresas e instituições locais, como, por exemplo, para compra de matérias primas, promoção de recursos de capacitação gerencial e formação profissional, criação de consórcios de exportação, contratação de serviços especializados, instituição de centros tecnológicos coletivos, cooperativas de crédito. Dessa soma resultaria a eficiência coletiva que, em princípio, determina a vantagem sustentável, o protagonismo social de instituições locais e o incentivo à humanização da produção pela integração das competências.

\section{Procedimentos metodológicos}

O estudo compara e analisa padrões. Preocupou-se em desenhar o padrão da distribuição municipal de meados da década de 70 (tomando como base o ano de 75) e início dos anos 80 (tomando como base o ano de 80), no sentido de avaliar as mudanças ocorridas nos mesmos durante estes 20 anos, comparando-se os fatores obtidos a análises recentes, referentes a 1996 e 2000. Isto faz sentido, pois as políticas de produtividade empresarial têm alta flexibilidade no tempo e supõem um intenso processo desburocratizante, de tal modo que municípios que tenham feito parte de um programa A possam, em pouco tempo, ser deslocados para programas B ou C, em razão de mudanças conjunturais ou mesmo estruturais e, até mesmo, que o conjunto de municípios com características semelhantes seja alterado e novos conjuntos possam ser formados. Tais 
agrupamentos comportam cidades de áreas geográficas diferentes que, por um tempo, são, fundamentalmente, iguais em propósitos. E em nível de desenvolvimento local, possibilitando a formação de redes de empresas e estudos de matrizes de competitividade. Usamos a análise fatorial como guia metodológico, numa tentativa de encontrar um denominador comum para as informações avulsas contidas nos censos, ou seja, englobar as características observadas num indicador completo e obtivemos fatores que permitem registrar o dinamismo das mudanças ambientais. Realizamos a nossa pesquisa a partir de dados secundários dos municípios do Estado de São Paulo, visando ao desenho de "clusters" estratégicos ${ }^{2}$ (Porter 1999, P.211). Devido à grande heterogeneidade entre as variáveis utilizadas quanto à área de atuação dos municípios, verificamos que uma única análise fatorial, com todas as variáveis, poderia fornecer uma solução com fatores de difícil interpretação, o que dificultaria uma proposta para a competitividade empresarial. Sugerimos, então, a formação de grupos homogêneos de variáveis, extraindo-se fatores independentes ou ortogonais de cada um. Utilizamos o método PCA (Principal Component Analysis) e o critério de rotação Varimax para obter fatores facilmente interpretáveis. Os fatores com maior explicação foram considerados em cada grupo (no máximo 2 fatores), alcançando-se um total de nove fatores, todos interpretáveis.

Para cada um desses grupos, foi aplicada uma Análise Fatorial extraindo-se, no máximo, dois fatores. Utilizou-se o método PCA com rotação Varimax e matriz de correlação (taxas padronizadas). Um resumo desse método, com os principais resultados obtidos, é exibido na seção seguinte.

\section{Descrição das variáveis utilizadas para visualização de pólos regionais de competência sustentável}

A escolha de variáveis para efetuar este mapeamento concentrou-se em dados secundários, ou seja, registros censitários, fornecidos pelas seguintes instituições: FIBGE, FSEADE, FUNDAP.

Foram escolhidos para este trabalho 126 municípios do Estado de São Paulo. A relação encontra-se no Apêndice A.1.

Abaixo segue a listagem das variáveis escolhidas para análise por município em 1975, 1980, 1996, 2000:

Quadro 1. Variáveis escolhidas para análise

\begin{tabular}{|c|l|}
\hline CNE & criação de novos empregos. \\
\hline LEC & ligações elétricas comerciais. \\
\hline LEI & ligações elétricas industriais. \\
\hline VPA & valor da produção agrícola. \\
\hline
\end{tabular}

2 Porter, M.E. Competição, RJ. Ed. Campus, 1999 - Um aglomerado é um grupamento geograficamente concentrado de empresas inter-relacionadas e instituições correlatas numa determinada área, vinculadas por elementos comuns e complementares. 


\begin{tabular}{|c|c|}
\hline $\mathrm{ICM}$ & arrecadação do ICMS. \\
\hline $\mathrm{RCM}$ & receita municipal. \\
\hline SMR & número de estabelecimentos de serviços de manutenção. \\
\hline CVE & número de estabelecimentos de comércio varejista. \\
\hline CAT & número de estabelecimentos de comércio atacadista. \\
\hline CPA & número de estabelecimentos de comércio de produtos alimentícios. \\
\hline CVP & número de estabelecimentos de comércio de veículos e peças. \\
\hline NEI & número de estabelecimentos industriais. \\
\hline IPA & número de estabelecimentos de indústrias de alimentos. \\
\hline MTL & número de estabelecimentos de indústrias metalúrgicas. \\
\hline MEC & número de estabelecimentos de indústrias mecânicas. \\
\hline ETM & número de estabelecimentos de extração e transformação de minérios. \\
\hline $\mathrm{ICV}$ & número de estabelecimentos de indústrias de calçados e vestuários. \\
\hline SLI & salários pagos pela indústria. \\
\hline VPI & valor da produção industrial. \\
\hline VTI & valor da transformação industrial. \\
\hline TRS & total da receita com serviços. \\
\hline TRC & total da receita com atividades comerciais. \\
\hline CQV & comércio de produtos químicos e farmacêuticos. \\
\hline POP & população do município em 1000 habitantes. \\
\hline
\end{tabular}

Para permitir a comparabilidade dessas variáveis entre os municípios ${ }^{3}$, transformamos as mesmas em taxas (por habitante, por 1.000 habitantes ou 10.000 habitantes). Essas taxas foram obtidas da seguinte forma:

a) As variáveis CNE, LEC, LEI, VPA, ICM e RMC foram transformadas em taxas por 1000 habitantes, dividindo-se o valor das mesmas pela população do município (em 1000 habitantes). Estas taxas foram denotadas precedendo-se as variáveis pela letra "T".

b) As variáveis SMR, CVE, CPA, CAT, CVP, IPA, NEI, MTL, ETM, ICV, CQV e MEC foram transformadas em taxas por 10.000 habitantes, dividindo-se o valor das mesmas pela população do município (data em 1000 habitantes) e multiplicando-se o valor obtido por 10. Utilizamos notação similar a a).

c) Finalmente, as variáveis SLI, VPI, VTI, TRS e TRC foram transformadas em taxas por habitante, dividindo-se o valor das mesmas pela população do município. Utilizamos notação similar a a).

Para evitar que valores aberrantes (pontos extremos) influenciassem demasiadamente a matriz de correlação e, em conseqüência, distorcessem os resultados finais, procedeu-se uma análise grandes empresas de atuação nacional ou global é focar o negócio nos atendimento de segmentos específicos do mercado regional em que elas estarão localizadas (Bassi, 2000). Podemos, portanto, analisar municípios a partir de sua inserção em uma matriz de competitividade local em que um dos eixos refere-se aos fatores críticos de sucesso ou fracasso de estratégias de negócios, e o eixo horizontal verifica tendências destes mesmos fatores críticos ao longo do tempo. 
descritiva no sentido de omitir, em cada caso, aqueles municípios que apresentassem tais valores em algumas das variáveis utilizadas. Adotamos como critério: omitir das análises aqueles municípios com valores acima/abaixo da média 3 desvios padrões. Posteriormente, para cada fator, estes municípios tiveram seus escores estimados. Foram formados, para análises, os seguintes grupos de variáveis:

Quadro 2. Grupos de variáveis

\begin{tabular}{|c|l|}
\hline GRUPO I & $\begin{array}{l}\text { Para apontar crescimento ou decréscimo municipal. Variáveis utilizadas: TCNE, TLEC, TLEI, TSMR e } \\
\text { TIRS. }\end{array}$ \\
\hline GRUPO II & $\begin{array}{l}\text { Para apontar características de um município segundo sua região. Variáveis utilizadas: TVPA, TICM, } \\
\text { TRMC e TCQV. }\end{array}$ \\
\hline GRUPO III & $\begin{array}{l}\text { Para apontar concentração em ramos tradicionais da economia. Variáveis utilizadas: TICV, TCPA, TIPA, } \\
\text { TCVE e TEIM. }\end{array}$ \\
\hline GRUPO IV & $\begin{array}{l}\text { Para apontar crescimento ou decréscimo comercial e industrial. Variáveis utilizadas: TMIL, TMEC, } \\
\text { TCAT, TCVP e TTRC. }\end{array}$ \\
\hline GRUPO V & Para apontar intensidade da industrialização. Variáveis utilizadas: TSLI, TVPI, TVTI e TNEI. \\
\hline
\end{tabular}

\section{Análise fatorial para mapear o Estado de São Paulo pela sustentabilidade de seus municípios}

Para cada grupo definido na seção anterior, denotaremos por $\mathrm{X}_{\mathrm{j}}$ a j-ésima taxa padronizada. Suponha que cada componente $X_{j}$ seja gerado como uma combinação linear de $q$ fatores não correlacionados e não observáveis (adotamos $q=2$ ), e mais um erro, i.e.,

$$
\begin{aligned}
& X_{1}=\lambda 1_{1} f_{1}+\ldots+\lambda 1_{q} f_{q}+e_{1} \\
& \vdots \\
& X_{p}=\lambda p_{1} f_{1}+\ldots+\lambda p_{q} f_{q}+e_{p(q<p)}
\end{aligned}
$$

$\mathrm{f}_{1}, \ldots, \mathrm{fq}_{\mathrm{q}}$ são os fatores comuns,

$\mathrm{e}_{1} \ldots .$, ep fatores específicos ou erros,

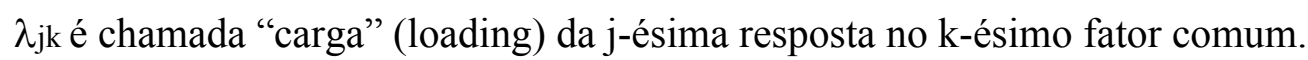


Supõe-se:

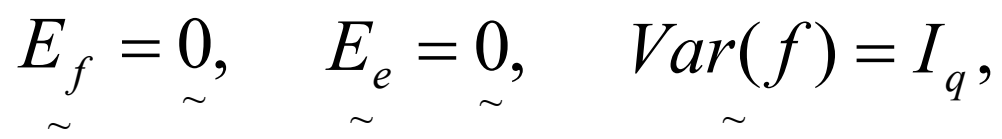

e

$$
\operatorname{Var}(\mathrm{e})=\psi=\operatorname{diag}\{\psi 1, \ldots, \psi \mathrm{p}\},
$$

onde $\psi \mathrm{j}$ é chamada variância específica, $e$ e $f$ são não correlacionados.

Observações:
a) $\quad \operatorname{Cov}\left(X_{j}, f k\right)=\lambda j k$,
b) $\quad \operatorname{Cov}\left(X_{j}, X_{j^{\prime}}\right)=\lambda_{j} 1 \lambda_{j^{\prime} 1}+\ldots+\lambda_{j p} \lambda_{j^{\prime}} p$,
c) $\quad \sigma^{2} \mathrm{jj}=\operatorname{Var}\left(\mathrm{X}_{\mathrm{j}}\right)=\lambda^{2} \mathrm{j} 1+\ldots \lambda^{2} \mathrm{jp}+\psi^{2} \mathrm{j}$,
d) $\quad \sigma_{\mathrm{jj}}-\psi^{2} \mathrm{j}=\lambda^{2} \mathrm{j} 1+\ldots=\lambda^{2} \mathrm{jp}$ é chamada comunalidade da resposta $\mathrm{j}$.

Para estimar $\Lambda=\left\{\lambda_{\mathrm{jk}}\right\}$ e $\psi$, utilizamos o método PCA. Este método é chamado de solução do fator principal e iguala os $\lambda_{\mathrm{jk}}$ 's às cargas dos q fatores principais, enquanto os $\psi_{\mathrm{j}}$ 's são estimados através das cargas dos $\mathrm{p}-\mathrm{q}$ fatores restantes.

Como os fatores em (1) não são únicos, utilizamos o critério de rotação Varimax, obtendo fatores que tenham cargas grandes para algumas variáveis e pequenas para outras.

A importância dos fatores nos municípios foi medida pelos escores dos fatores, estimando-se o vetor de parâmetros B na expressão abaixo.

$$
\underset{\sim}{f}=\underset{\sim}{X B}+\underset{\sim}{e}
$$

Mesmo não se conhecendo valores observados para $\mathrm{f}$, é possível estimar $\mathrm{B}$, similarmente à regressão linear, pois tem-se estimativas de covariância entre f e X, e da matriz de covariância de X. Logo, tem-se:

$$
\hat{B}_{T}=\hat{\Delta}_{T}\left(\hat{\Delta} \hat{\Delta}_{T}+\hat{\psi}\right)^{-1}
$$


E a importância do k-ésimo fator no l-ésimo município será estimada por:

$$
\hat{f}_{k l}=\sum_{j=1}^{P} x_{l j} \hat{B}_{j}
$$

onde $\mathrm{x}_{\mathrm{lj}}$ é o valor padronizado da j-ésima taxa no 1-ésimo município, sendo, então, obtidos os seguintes resultados fatoriais: Foram extraídos no máximo 2 fatores para cada grupo de variáveis (que, em geral, deram uma explicação de aproximadamente $70 \%$ da variância total dos fatores) obtendo-se os seguintes resultados para 1975, 1980, que apresentados nos apêndices A.2 e A.3, respectivamente e, para 1996 e 2000, tal como interpretados.

Quadro 3. Fatores

\begin{tabular}{|c|l|}
\hline \multirow{2}{*}{ Grupo 1 } & Fator 1 Receita municipal no setor de serviços. \\
\cline { 2 - 2 } & Fator 2 Criação de empresas locais. \\
\hline \multirow{2}{*}{ Grupo 2} & Fator 3 Nível de receitas municipais e arrecadação de ICMS. \\
\cline { 2 - 2 } & Fator 4 Nível de produção agrícola no município. \\
\hline \multirow{2}{*}{ Grupo 3 } & Fator 5 Grau de desenvolvimento do comércio varejista local. \\
\cline { 2 - 2 } & Fator 6 Grau de desenvolvimento da indústria de vestuário, calçados e alimentos. \\
\hline \multirow{2}{*}{ Grupo 4 } & Fator 7 Grau de desenvolvimento do setor atacadista quanto a receitas comerciais totais. \\
\cline { 2 - 2 } & Fator 8 Grau de desenvolvimento da indústria mecânica e metalúrgica local. \\
\hline Grupo 5 & Fator 9 Índice de industrialização global. \\
\hline
\end{tabular}

A importância dos fatores nos municípios foi mensurada pelas estimativas dos escores fatoriais, sendo estas quantidades utilizadas na formação dos grupamentos de municípios. Diversos conjuntos de grupamentos foram formados, alguns obtidos de fatores individuais, enquanto outros, segundo pares de fatores com atuação conjunta num mesmo setor dos municípios. Foi, também, obtido, para cada ano, um mapeamento do Estado de São Paulo segundo todos os fatores. Utilizamos, para formação desses conjuntos de grupamentos, o método de "clusters" k-mean. Vale ressaltar que, neste trabalho, os escores fatoriais utilizados na formação dos grupamentos são computados numa mesma escala, sem privilegiar qualquer fator, pois não é nosso objetivo quantificar a "real" importância de cada fator nos municípios, mas sim, agrupar os últimos conforme a proximidade de seus escores fatoriais que são bons indicadores da situação dos municípios no Estado de São Paulo. Logo, qualquer atribuição diferenciada de pesos aos fatores e em conseqüência aos escores fatoriais, tornaria o trabalho menos informativo com os grupamentos sendo determinados pelos fatores de maior peso, prejudicando, assim, a formação de grupamentos semelhantes segundo os outros fatores, que também são importantes, visto que representam variáveis de relevância na proposta empresarial de criação de pólos produtivos regionais e estratégicos.

Além disso, se conhece muito pouco sobre critérios de ponderação, e qualquer um que fosse adotado poderia dirigir os resultados conforme interesses do pesquisador. 
Finalmente, observamos que alguns dos mapeamentos foram obtidos segundo fatores individuais, logo os grupamentos formados nestes casos permaneceriam inalterados com a atribuição de pesos diferenciados aos fatores, pois estaríamos procedendo apenas uma mudança de escala nos escores fatoriais.

\section{Formação dos grupamentos descritivos dos aglomerados regionais}

Utilizando o método de “clusters" k-means, procuramos, através dos escores fatoriais, criar novos mapeamentos do Estado de São Paulo, cada um com 10 (dez) grupamentos homogêneos, por este apresentar valores para o teste de diferença de médias altamente significativas, para os anos de 1975 e 1980, 1996 e 2000. O principal objetivo é contrapor estes grupamentos às atuais áreas administrativas do Estado, visando a romper, para efeito de análise, os mesmos contornos geográficos que formam a base das atuais divisões do Estado de São Paulo. Estes grupamentos indicam que, em cidades semelhantes, é possível propor programas semelhantes de desenvolvimento sustentado, auxiliando no desenvolvimento de clusters regionais diferenciados ${ }^{3}$, mas que constituam perfis de competência complementares.

Estes grupamentos foram formados segundo fatores específicos, segundo grupo de fatores com atuação semelhante num mesmo setor dos municípios e segundo todos os fatores simultaneamente. No entanto, é bom ressaltar que o fato de duas cidades constarem no mesmo grupamento não significa que suas características sejam idênticas e que a solução de seus problemas seja a mesma, porém, indica ao longo do tempo sua sustentabilidade.

Os mapeamentos obtidos são apresentados nos Apêndices A.1 a A.3. A seguir, exibimos alguns resultados e conclusões parciais. Considerando em conjunto os nove fatores, foram obtidos 10 grupamentos para o Estado de São Paulo, para os anos de 1975 e 1980. Apresentamos, a seguir, as principais características de cada grupamento, enquanto, nos Apêndices A.2 e A.3 são exibidos os clusters regionais apontados pelos fatores "clusters" encontrados para 1996 e 2000 são interpretados pelo pesquisador, apontando extenso desenvolvimento de áreas prestadoras de serviços no entorno a 200-250 Km da Grande São Paulo e a concentração de pólos de alta tecnologia ao longo do Vale do Paraíba, Campinas e São Carlos, de uma área agrícola dispersa, mas importante, e pólos logísticos ainda incipientes.

1975 - Os municípios de cada grupamento estão enumerados no Apêndice A.2.

Quadro 4. Grupamentos

\begin{tabular}{|l|l|}
\hline Grupamento 1: & $\begin{array}{l}\text { Taxas de criação de novos empregos dependentes de atividade industrial e fortemente } \\
\text { especializada de setor varejista, baixa concentração em serviços de reparação. }\end{array}$ \\
\hline Grupamento 2: & $\begin{array}{l}\text { Município predominantemente agrícola, com desenvolvimento de indústrias tradicionais, mas } \\
\text { pouco geradoras de emprego, setor varejista e atacadista bem abaixo da média, indústrias em } \\
\text { ascensão. }\end{array}$ \\
\hline
\end{tabular}




\begin{tabular}{|l|l|}
\hline Grupamento 3: & $\begin{array}{l}\text { Taxa alta de criação de empregos decorrentes de forte desenvolvimento do setor atacadista, } \\
\text { demonstrando importância dos elos regionais locais. }\end{array}$ \\
\hline Grupamento 4: & $\begin{array}{l}\text { Baixo índice de criação de empregos, arrecadação declinante, altas taxas de produção } \\
\text { agrícola, ausência de industrialização ainda que tradicional. }\end{array}$ \\
\hline Grupamento 5: & $\begin{array}{l}\text { Região turística - onde as altas taxas de criação de novos empregos vem de atividades } \\
\text { especializadas. }\end{array}$ \\
\hline Grupamento 6: & $\begin{array}{l}\text { Áreas homogêneas, caracterizadas por desenvolvimento recente, voltadas para a sobrevivência } \\
\text { no âmbito de atividades varejistas locais, sem funções especializadas no âmbito regional. }\end{array}$ \\
\hline Grupamento 7: & $\begin{array}{l}\text { Áreas em declínio no setor de serviços, e de pouca expansão no comércio varejista - sem } \\
\text { industrialização de porte complementar. }\end{array}$ \\
\hline Grupamento 8: & $\begin{array}{l}\text { Municípios ricos e fortemente industrializados, com indústria dinâmica e ricos em } \\
\text { arrecadação municipal. }\end{array}$ \\
\hline Grupamento 9: & $\begin{array}{l}\text { Municípios com índices elevados de atividades e entrepostos comerciais, o que indica alta } \\
\text { importância de atividades regionais, com níveis de industrialização médios e diversificados. }\end{array}$ \\
\hline Grupamento 10: & $\begin{array}{l}\text { Áreas de pequena arrecadação municipal e índices abaixo dos padrões do Estado. Tendência } \\
\text { ao empobrecimento relativo. }\end{array}$ \\
\hline
\end{tabular}

1980 - Os municípios de cada grupamento estão enumerados no Apêndice A.3

Quadro 5. Novos grupamentos

\begin{tabular}{|l|l|}
\hline Grupamento 1: & Área economicamente estável, com baixa densidade populacional, sem diversificação local. \\
\hline Grupamento 2: & $\begin{array}{l}\text { Municípios com baixa arrecadação de receitas municipais e Imposto de Circulação de } \\
\text { Mercadorias - dependente de atividades secundárias especializadas, pouca diversificação } \\
\text { empresarial, produção predominantemente agrícola e industrialmente especializada e pouco } \\
\text { diversificada. }\end{array}$ \\
\hline Grupamento 3: & $\begin{array}{l}\text { Áreas de desenvolvimento recente com predomínio acentuado de atividades comerciais e } \\
\text { expansão para poder atender à demanda de uma população em crescimento, com prioridade } \\
\text { para entrepostos comerciais e industriais de ramos tradicionais. }\end{array}$ \\
\hline Grupamento 4: & $\begin{array}{l}\text { Área de quase pleno emprego, graças ao setor varejista altamente desenvolvido, pólos regionais } \\
\text { de compra e consumo, pequena industrialização. }\end{array}$ \\
\hline Grupamento 5: & $\begin{array}{l}\text { Bom nível de emprego - decorrente de áreas de industrialização dinâmica, sem que isto gere } \\
\text { desenvolvimento local ou regional, com pequeno número de indústrias tradicionais e declínio } \\
\text { da produção agrícola. }\end{array}$ \\
\hline Grupamento 6: & $\begin{array}{l}\text { Áreas fortemente carentes de empresas industriais de setores tradicionais e de atividades } \\
\text { comerciais de atacado e distribuição com índices de industrialização na média e não } \\
\text { diversificados, mas cuja população estável vive de acordo com os padróes médios do Estado. }\end{array}$ \\
\hline Grupamento 7: & $\begin{array}{l}\text { Áreas de receitas altas em arrecadação de tributos, industrialização não diversificada, baixa } \\
\text { atividade comercial, falta de empregos. }\end{array}$ \\
\hline Grupamento 8: & $\begin{array}{l}\text { Áreas mal desenvolvidas, falta de empregos locais, pequeno desenvolvimento de comércio } \\
\text { varejista, atacadista e de indústrias tradicionais. }\end{array}$ \\
\hline Grupamento 9: & $\begin{array}{l}\text { Áreas abaixo da média em arrecadação municipal e na média em indústrias tradicionais e } \\
\text { abaixo da média em indústrias dinâmicas, com nível de emprego estável. }\end{array}$ \\
\hline Grupamento 10: & $\begin{array}{l}\text { Municípios que passam a ter importância regional, áreas acima da média em arrecadação } \\
\text { municipal, industrialização diversificada localmente e área comercial desenvolvida } \\
\text { recentemente. }\end{array}$ \\
\hline
\end{tabular}

Através dos dados históricos posicionamos os municípios ${ }^{4}$ durante o período de 75 e 80 nos diferentes grupamentos, vide anexos A1, A2 e A3. Tendo como exemplos estas formações regionais, podemos afirmar que se isto tivesse sido estimulado pelo empreendedorismo na época, muitos municípios e regiões não teriam decaído, pois já possuíam fortes indicativos de 
competências locais, entretanto, não havia à época incentivos à produção dos pólos, arranjos produtivos locais ou mesmo para o começo das incubadoras de empresas locais de tecnologia, com isso, chegamos a um novo mapeamento este referente ao período 1996-2000.Restando muito a fazer para o resgate de indústrias tradicionais. Esperamos que nosso olhar sobre aqueles clusters possa auxiliar em sua estratégia competitiva, apontando para soluções com melhor visibilidade estratégica regional, apontando o desenvolvimento de 4 pólos logísticos no Estado de São Paulo, a saber: (1) Grande São Paulo e seu entorno a $250 \mathrm{Kms}$ circulares; (2) pólos de alta tecnologia; (3) pólo agrícola; (4)pólos comerciais e de desenvolvimento logístico

O primeiro pólo caracteriza-se por crescimento do setor de serviços e diminuição da atividade industrial, reflexos da globalização da última década, que sucateou o parque industrial pouco competitivo existente na região metropolitana e tornou os mega-aglomerados urbanos de países emergentes voltados para prestação de serviços. Nossa pesquisa detectou um pólo prestador de serviços num raio de $250 \mathrm{Kms}$ da capital de São Paulo, uma cidade global.

Segundo pólo - o de alta tecnologia - tem São Carlos, no interior, e São José dos Campos e demais cidades no eixo da Rodovia Dutra, que liga São Paulo ao Rio de Janeiro, como expressão da indústria globalizada e está voltado para a exportação, tendo excluído muitos parceiros locais. É o caso do Embraer que possui parceiros americanos e chineses, a logística, neste caso está voltada para parceiros externos.

O terceiro pólo - agrícola, tem sofrido grandes alterações, estando diluído em diferentes regiões do Estado de São Paulo

Tabela 1. Valor da Produção Agropecuária por Região Administrativa do Estado de São Paulo - 2001

\begin{tabular}{|c|c|c|}
\hline RA & Valor da Produção (R\$) & $\%$ \\
\hline Campinas & $3.302 .391 .485,05$ & 19,03 \\
\hline Sorocaba & $2.120 .734 .791,72$ & 12,22 \\
\hline S.J.Rio Preto & $1.844 .523 .263,33$ & 10,63 \\
\hline Central (Araraquara) & $1.547 .334 .742,46$ & 8,92 \\
\hline Marília & $1.444 .155 .837,87$ & 8,32 \\
\hline Araçatuba & $1.194 .981 .866,76$ & 6,89 \\
\hline Bauru & $1.161 .204 .840,63$ & 6,69 \\
\hline Franca & $1.089 .139 .449,60$ & 6,28 \\
\hline Ribeirão Preto & $1.054 .272 .709,95$ & 6,08 \\
\hline Presidente Prudente & $959.478 .588,40$ & 5,53 \\
\hline Barretos & $996.032 .270,82$ & 5,74 \\
\hline S.José dos Campos & $214.988 .268,44$ & 1,24 \\
\hline Registro & $210.325 .433,40$ & 1,21 \\
\hline São Paulo & $186.776 .507,27$ & 1,07 \\
\hline Baixada Santista & $26.884 .665,99$ & 0,15 \\
\hline Total & $17.353 .224 .721,69$ & 100 \\
\hline
\end{tabular}

(Fonte: IEA/APTA/SAA-SP) 
Este pólo demonstra que o agro-negócio deu sustentabilidade estratégica a diversas regiões do Estado, antes mais dispersas e empobrecidas., mas a logística torna-se vital para expandi-lo. O quarto pólo é o logístico, que está sendo formado ao longo da região do Grande ABC paulista, o qual, no futuro, estará permitindo expansão do setor serviços. Tal como podemos notar nos grupamentos mapeados em 1996 e 2000. Os principais incentivos que levam uma empresa a participar de um cluster são ganhos de escala. A parceria permite a aquisição de novas tecnologias e também abre portas para a exportação, que exige um volume maior de produção, o agro-negócio alimenta a cadeia logística. Piracicaba, por exemplo, é um pólo logístico, a partir da indústria que fabrica equipamentos pesados, máquinas rodoviárias, exportando para 130 países, incentivando outros processos de complementação industrial e de distribuição, podendo constituir-se num pólo logístico. O mesmo ocorre em Botucatu, onde a indústria de produção de aeronaves agrícolas para pulverização do arroz, soja e algodão criam um processo comercial ascendente e gerador de emprego, igualmente, na região de Marília com a fabricação de máquinas para pulverizar o solo, estas regiões são naturais áreas logísticas do agro-negócios. Na região do ABC paulista forma-se um grande pólo logístico, dada a proximidade da região a diferentes portos, vias aéreas, rodoviárias e ferroviárias.

\section{A evolução - mapeamento 1996/2000}

Foram extraídos, no máximo, dois fatores para cada grupo de variáveis que, em geral, deram uma explicação de $70 \%$ da variância total.

Quadro 6. Mapeamento

\begin{tabular}{|c|c|c|c|}
\hline \multicolumn{2}{|r|}{ GRUPAMENTOS } & MAPEAMENTO 1996 & MAPEAMENTO 2000 \\
\hline $1 / 10$ & Área de forte predomínio agrícola. & $\begin{array}{l}\text { Barretos, S.J. do Rio Preto Vista, } \\
\text { Araçatuba, Sorocaba, Marília. }\end{array}$ & $\begin{array}{l}\text { S.J. do Rio Preto, Araçatuba, } \\
\text { Marília, Sorocaba, Cândido Mota. }\end{array}$ \\
\hline $2 / 10$ & $\begin{array}{l}\text { Bom nível de emprego decorrente da } \\
\text { industrialização dinâmica. }\end{array}$ & $\begin{array}{l}\text { São Carlos, Santa Bárbara, Porto } \\
\text { Ferreira. }\end{array}$ & $\begin{array}{l}\text { Santa Bárbara, Rio Claro, Porto } \\
\text { Ferreira. }\end{array}$ \\
\hline $3 / 10$ & $\begin{array}{l}\text { Área de população estável, com } \\
\text { predomínio de atividades comerciais. } \\
\text { Possíveis pólos logísticos do agro- } \\
\text { negócio. }\end{array}$ & São José do Rio Preto, Itapetininga. & $\begin{array}{l}\text { Botucatu, Assis, Mogi-Mirim, } \\
\text { Itapetininga. }\end{array}$ \\
\hline $4 / 10$ & $\begin{array}{l}\text { Áreas de declínio, sem industrialização } \\
\text { de porte e poucas atividades comerciais. }\end{array}$ & Apiaí, Salto, Itapeva, Ribeirão Bonito. & São Roque, São Simão. \\
\hline $5 / 10$ & $\begin{array}{l}\text { Áreas de desenvolvimento recente, sem } \\
\text { funções especializadas de nível } \\
\text { regional. }\end{array}$ & Itapetininga, Tupã, Marília. & $\begin{array}{l}\text { Bebedouro, Lençóis Paulista, } \\
\text { Presidente Prudente, Jaboticabal. }\end{array}$ \\
\hline $6 / 10$ & $\begin{array}{l}\text { Áreas abaixo da média em arrecadação } \\
\text { municipal, mas com nível de emprego } \\
\text { estável. }\end{array}$ & $\begin{array}{l}\text { Assis, Bebedouro, Itapeva, Lençóis } \\
\text { Paulista, Ribeira. }\end{array}$ & Jaú, Águas da Prata, Cabreúva. \\
\hline
\end{tabular}




\begin{tabular}{|c|c|c|c|}
\hline $7 / 10$ & $\begin{array}{l}\text { Áreas de industrialização diversificada, } \\
\text { alta arrecadação de tributos e falta de } \\
\text { empregos. Possíveis pólos logísticos da } \\
\text { indústria tradicional. }\end{array}$ & Mogi-Guaçu, Rio Claro. & $\begin{array}{l}\text { Birigui, Bauru, Franca, Ribeirão } \\
\text { Preto. }\end{array}$ \\
\hline $8 / 10$ & $\begin{array}{l}\text { Áreas de pequena arrecadação } \\
\text { municipal e tendência ao } \\
\text { empobrecimento relativo. }\end{array}$ & Andradina, Atibaia. & Andradina, Ribeira. \\
\hline $9 / 10$ & $\begin{array}{l}\text { Área comercial desenvolvida } \\
\text { recentemente e indústria tradicional. } \\
\text { Possíveis pólos logísticos. }\end{array}$ & $\begin{array}{l}\text { Presidente Prudente, Ribeirão Preto, } \\
\text { Bauru, Itu, São Simão. }\end{array}$ & $\begin{array}{l}\text { Lins, Itu, Novo Horizonte, } \\
\text { Descalvado, São Simão. }\end{array}$ \\
\hline $10 / 10$ & $\begin{array}{l}\text { Áreas em expansão no setor de serviços. } \\
\text { Pólos logísticos em serviços }\end{array}$ & $\begin{array}{l}\text { Americana, Jundiaí, Piracicaba, área } \\
\text { metropolitana de São Paulo }\end{array}$ & $\begin{array}{l}\text { Americana, São Carlos, Jundiaí, } \\
\text { Atibaia,área metropolitana de São } \\
\text { Paulo }\end{array}$ \\
\hline
\end{tabular}

* As demais cidades escolhidas não alteraram sua posição relativa.

A organização das empresas em arranjos constitui-se em importante fonte geradora de vantagens competitivas duradouras, principalmente quando estas são construídas a partir de enraizamento de capacidades produtivas e inovadoras locais.

Arranjos produtivos são aglomerações de empresas localizadas em um mesmo território, que apresentam especializações produtivas e mantêm algum vínculo de articulação, interação cooperação e aprendizagem entre si e com outros atores locais tais como, governo, associações empresariais, instituições de créditos, ensino e pesquisa.

Um Arranjo Produtivo Local é caracterizado pela existência da aglomeração de um número significativo de empresas que atuam em torno de uma atividade produtiva principal. Para isso, é preciso considerar a dinâmica do território em que essas empresas estão inseridas, tendo em vista o número de postos de trabalho, faturamento, mercado, potencial de crescimento, diversificação, entre outros aspectos, da humanização da produção.

Por isso, a noção de território é fundamental para a atuação em Arranjos Produtivos Locais. No entanto, a idéia de território não se resume apenas à sua dimensão material ou concreta. Território é um campo de forças, uma teia ou rede de relações sociais que se projetam e um determinado espaço. O quadro a seguir ilustra isso.

Quadro 7. Setores

\begin{tabular}{|c|c|}
\hline Setor & Municípios ou localidades \\
\hline $\begin{array}{l}\text { Ourivesaria ( Ourivesaria e Lapidação de pedras semi- } \\
\text { preciosas, jóias) }\end{array}$ & Limeira e São José do Rio Preto \\
\hline Confecções & Tabatinga, Ibitinga,,Conchas, Cerquilho \\
\hline Madeira e Móveis (Móveis) & Mirassol \\
\hline Construção Civil ( Cerâmica Vermelha) & Vargem Grande do Sul \\
\hline Calçados ( Calçados femininos) & Jaú \\
\hline Calçados( Calçados Masculinos) & Franca \\
\hline Calçados( Calçados Infantis) & Birigui \\
\hline Automotivo (Auto peças/plástico) & Santo André \\
\hline
\end{tabular}




\begin{tabular}{|l|l|}
\hline \multicolumn{1}{|c|}{ Setor } & \multicolumn{1}{c|}{ Municípios ou localidades } \\
\hline Madeira e Móveis( Móveis de madeira) & São Bernardo do Campos \\
\hline Petróleo e Gás & Paulínia \\
\hline
\end{tabular}

O pólo têxtil de Americana é considerado o maior núcleo de produção de tecidos artificiais e sintéticos do país, responsável por $85 \%$ da produção nacional de mais de 130 milhões de metros lineares por ano. Apesar deste grande potencial, o volume confeccionado não chega a $1 \%$ do total de embarques têxteis da região, segundo dados do Centro das Indústria do Estado de São Paulo (Ciesp) de Americana.

Para fortalecer o setor composto por 700 indústrias de fiação e tecelagem e especializada em tinturaria e estamparia na região de Americana, Nova Odessa, Santa Bárbara, Sumaré e Hortolândia e 2,5 mil confecções da região foi criado um cluster para que as cadeias produtivas possam trabalhar em conjunto e criar em seu redor um amplo agregado de empresas prestadoras de serviços. Têm sido intensificadas ações em clusters em formação como o de confecções de Cerquilho e Tietê; outras ações locais incluem cerâmica vermelha e revestimento em Tambaú, Santa Getrudes, e vinhos e uva em Jundiaí e Louveira.

As duas últimas décadas, por razões conhecidas, levaram a economia a fortes oscilações e afetaram a estratégia das empresas e de grupos setoriais e pólos regionais. Isto alterou significativamente a posição dos grupamentos de municípios que tínhamos em 1975 e 1980, mas não afetou, significativamente, a maioria dos municípios, pois o crescimento do Estado de São Paulo, na última década, foi menor que o esperado. Só o empreendedorismo protagonista pode mudar o modelo, desenhando novos arranjos produtivos. Amato Neto (2000) destaca o pólo coureiro-calçadista de Franca, Birigui e Jaú que, em nossa análise referente a 75-80, não estavam nos mesmos grupamentos e eram comparativamente menos expressivos que outras cidades ou regiões. A partir de 84, devido a mini-desvalorizações cambiais, estas cidades tornaram-se pólos exportadores calçadistas e, apesar de poucos investimentos, a maior parte deles em equipamentos eletrônicos, o setor viu o preço médio de seu produto subir no mercado internacional. O Brasil não compete com o calçado italiano de preço alto e produz um produto melhor que os asiáticos. Franca especializou-se em calçados masculinos em couro, Birigui em infantis sintéticos e Jaú, em calçados femininos, todos em couro, com forte relação de cooperação entre as empresas. Outro exemplo de redirecionamento está em Americana, onde o complexo industrial têxtil-confecções alterou significativamente seu perfil tecnológico, após enfrentar dura perda e para artigos estrangeiros (especialmente os chineses), Atualmente, já se pode falar em pólo têxtil onde poderiam estar Jundiaí, Americana, Araraquara, São José dos Campos, Sorocaba e Itapetininga. Outros pólos referidos por Amaro Neto incluem cerâmicas em algumas regiões da Grande São Paulo, Porto Ferreira e Itú. Desde 1982, a principal cerâmica de Porto Ferreira não fabrica mais louça, e sim 
pisos cerâmicos, redirecionando seus negócios para materiais de acabamento em construção civil, Tambaú, Cordeirópolis vêm se destacando, junto com Santa Gertrudes.

\section{Conclusões finais}

Diversas crises recessivas impediram o desenvolvimento integrado dos pólos logísticos no Estado de São Paulo, a concepção logística eficiente permite às regiões geográficas a constituição de redes de apoio. Grupamentos logísticos são um fator chave para estimular a agricultura, a indústria, o comércio e os serviços.

A obsessão pela competividade faz com que se reavaliem estratégias para o Estado de São Paulo, que perdeu o fôlego nas últimas décadas, por meio de políticas e estratégias públicas e privadas, tornando-o um grande pólo de sustentabilidade logística nos próximos cinco anos, se a iniciativa privada for estimulada através de redes locais. $O$ mapeamento deve ser feito regularmente, e servir como indicador de posições estratégicas, e apontar áreas logísticas sustentáveis, bem como a evolução do setor de serviços locais. Estas conclusões ainda chamam a atenção para as articulações de cooperação e aprendizagem em arranjos produtivos locais, o que permite gerar empregos especializados, treinar mão-de-obra local e intensificar a qualidade dos produtos destinados à exportação, redesenhando, na prática o Estado de São Paulo, a partir de seu perfil de competências. O primeiro pólo que descrevemos caracterizado pelo setor serviços será o que permitirá o desenvolvimento crescente do quarto pólo de distribuição, ambos formando dois grandes anéis na região que vai do $\mathrm{ABC}$ a Campinas. Transversalmente, podemos visualizar o pólo de alta tecnologia de São Carlos ao Vale do Paraíba e em sentido inverso o pólo de agro-negócios que vai da região de Barretos e Araçatuba a Sorocaba e Registro. Como conclusão, ainda, podemos apontar que as Universidades espalhadas pelo Estado de São Paulo desempenharão um importante papel no desenvolvimento de novos arranjos produtivos locais.

Os quatro pólos estratégicos detectados pela pesquisa dos “clusters", já, podiam ser entrevistos no trabalho publicado pelo SEBRAE-SP, em 1994, de autoria de Santos, S.A., Pereira, H.J. e França, S.E., “Cooperação entre micro e pequenas empresas”. Além disso, a análise do perfil de investimentos no Estado de São Paulo aponta o Vale do Paraíba com aproximadamente 35\% do capital investido no Estado, a região de Campinas com 27\%, a Grande São Paulo com 11\% e o restante distribuído pelo território paulista, denotando aporte de recursos no pólo de alta tecnologia, no Vale do Paraíba, mais investimentos no setor de serviços característicos da Grande São Paulo e região de Campinas, e o restante muito disperso entre atividades comerciais e de entrepostos, sendo o agronegócio gerador de recursos no Estado, e apresentando crescimento na última década, como responsável pela ascensão de muitos municípios paulistas, mas ainda dispersos. Atividades comerciais e logísticas ainda não estão bem definidas no Estado de São Paulo e são uma boa 
oportunidade para a construção de redes locais. A logística é uma nova ordem das coisas, de vital importância estratégica, tendo importância em escala global, regional e local, com funções comerciais mais especializadas.

\begin{abstract}
This article considers the evolution of the logistic sustentability of cities in State of São Paulo at different historical moments, understanding it as essential strategical ability that it allows the humanization of the production, through clusters and information sharing between companies, which has multiplying effect for management of intangible resources such as the knowledge and the managerial development. We also examine, the degree of municipal development along three successive decades, 70's, 80's and 90's, and the formation of four great logistic polar regions, from aglomeration of companies and colaboratives local institutions of work, with insertion of man power. The article also points the recognition of these polar regions and its mapping as significant contribution to measure the impacts of the operations in the physical and human environment of the productive areas. The methodology used was the factorial analysis which indicated diverse factors of logistic sustentability in the regions of the state São Paulo.
\end{abstract}

Key-words:environment; clusters; sustentability.

\title{
Referências Bibliográficas
}

ALVAREngA, Paula G. Uma Proposta de Multigestão Empresarial para o Estado de São Paulo. IME, USP, 1987, mímeo.

Amato Neto, J. Redes de Cooperação Produtiva e Clusters Regionais, São Paulo, Atlas, 2000.

BASSI, Eduardo. Empresas Locais e Globalização. São Paulo, Cultura, 2000.

MANCE, E.A. A produção das redes. Petrópolis, Vozes, 2000.

PORTER, M.E. Competição, RJ, Campus, 1999.

VILlassante, T. Redes Alternativas Estratégicas e Estilos Criativos na Complexidade Social. Petrópolis, Vozes, 2002.

\section{Apêndice A.1. Regiões selecionadas por critério do pesquisador.}

$\mathbf{1}^{\text {a }}$ Região - fortemente atraída pela capital do Estado.

1.Itu, 2.Jundiaí, 3.Sorocaba, 4.Atibaia, 5.Itapetininga, 6.Porto Feliz, 7.Bragança Paulista, 8.Campinas, 9.Piracicaba, 10.São Roque, 11.Tietê, 12.Piracaia, 13.Cabreúva, 14.Indaiatuba, 15.Santa Bárbara, 16.São Pedro, 17.Salto, 18.Rio das Pedras, 19.Laranjal, 20.Americana.

$2^{\mathbf{a}}$ Região - formada no eixo servido pela antiga Cia.Mogiana de Estradas de Ferro

21.Mogi-Mirim, 22.Franca, 23.Lindóia, 24.Batatais, 25.Casa Branca, 26.Amparo, 27.Itapira, 28.S.João da Boa Vista, 29.Serra Negra, 30.São Simão, 31.Cajuru, 32.Socorro, 33.Ribeirão Preto, 34.Mococa, 35.Igarapava, 36.Patrocínio Paulista, 37.Mogi-Guaçu, 38.Ituverava, 39.S.J. do Rio Preto, 40.Sertãozinho, 41.Cravinhos, 42.Orlândia, 43.S.Joaquim da Barra, 44.Morro Agudo, 45.Serra Azul, 46.Águas da Prata, 47.Pontal.

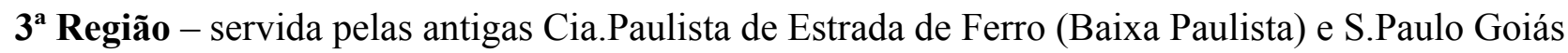


48.Araraquara, 49.Limeira, 50.Rio Claro, 51.São Carlos, 52.Descalvado, 53.Pirassununga, 54.Jaboticabal, 55.Araras, 56.Barretos, 57.Santa Rita, 58.Bebedouro, 59.Porto Ferreira, 60.Monte Azul, 61.Guairá, 62.Itirapina.

$4^{\text {a }}$ Região - servida pelo prolongamento da antiga Cia.Paulista e pela Estrada de Ferro Araraquara.

63.Brotas, 64.Jaú, 65.Dois Córregos, 66.Ribeirão Bonito, 67.Ibitinga, 68.Bariri, 69.Itápolis, 70.Bocaina, 71.Pederneiras, 72.Taquaritinga, 73.Nova Europa, 74.Dourado, 75.Boa Esperança, 76.Matão, 77.Barra Bonita, 78.Santa Adélia, 79.Catanduva, 80.Novo Horizonte, 81.Mirassol, 82.Pindorama.

$\mathbf{5}^{\mathbf{a}}$ Região - formada pelos municípios desenvolvidos ao longo da antiga E.F.Noroeste do Brasil e Alta Paulista.

83.Bauru, 84.Piratininga, 85.Penápolis, 86.Pirajuí, 87.Lins, 88.Avaí, 89.Araçatuba, 90.Birigui, 91.Promissão, 92.Avanhandava, 93.Cafelândia, 94.Garça, 95.Marília, 96.Andradina, 97.Tupã, 98.Pereira Barreto.

$\mathbf{6}^{\mathbf{a}}$ Região - formada ao longo da antiga Estrada de Ferro Sorocabana.

99.Botucatu, 100.Lençóis, 101.Avaré, 102.Santa Cruz do Rio Pardo, 103.Bofete, 104.Piraju, 105.São Manoel, 106.Itatinga, 107.S.Pedro do Turvo, 108.Agudos, 109.Salto Grande, 110.Assis, 111.Cerqueira César, 112.Ourinhos, 113.Palmital, 114.Presidente Prudente, 115.Chavantes, 116.Cândido Mota, 117 .Presidente Venceslau, 118.Regente Feijó.

$7^{\text {a }}$ Região - formada ao longo do ramal de Itararé da antiga Estrada de Ferro Sorocabana.

119.Itapeva, 120.Capão Bonito, 121.Itaporanga, 122.Iporanga, 123.S. Miguel Arcanjo, 124.Itararé,125.Ribeira, 126.Apiaí.

\section{Apêndice A.2 Mapeamento - 1975, segundo todos os fatores, utilizando rotação Varimax.}

1/10: 23.Lindóia.

2/10: 18.Rio das Pedras.

3/10: 58.Bebedouro, 100.Lençóis.

4/10: 38.Ituverava, 44.Morro Agudo, 47.Pontal, 60.Monte Azul, 66.Ribeirão Preto, 69.Itápolis, 73.Nova Europa, 74.Dourado, 78.Santa Adélia, 93.Cafelândia, 6.Porto Feliz, 35.Igarapava, 71.Pederneiras, 72. Taquaritinga, 54.Jaboticabal.

5/10: 29.Serra Negra.

6/10: 19.Laranjal, 27. Itapira, 34. Mococa, 45.Serra Azul, 52.Descalvado, 65.Dois Córregos, 80.Novo Horizonte, 82.Pindorama,118.Regente Feijó, 120.Capão Bonito, 121.Itaporanga, 122.Iporanga, 4.Atibaia, 5.Itapetininga, 46.Águas da Prata, 84.Piratininga, 70.Bocaina, 21.MogiMirim, 92.Avanhandava, 7.Bragança Paulista,16.São Pedro.

7/10: 10.São Roque, 12.Piracaia, 13.Cabreúva, 25.Casa Branca, 30.São Simão, 36.Patrocínio Paulista, 39.S.J. do Rio Preto, 75.Boa Esperança, 88.Avaí, 91.Promissão, 96.Andradina, 98.Pereira Barreto, 103.Bofete, 106.Itatinga, 107.S.Pedro do Turvo, 109.Salto Grande, 108.Agudos, 113.Palmital, 115.Chavantes, 116.Cândido Mota, 119.Itapeva, 123.S. Miguel Arcanjo, 125.Ribeira, 126.Apiaí.

8/10: 15.Santa Bárbara, 17.Salto, 20.Americana, 37.Mogi-Guaçu, 40.Sertãozinho, 49.Limeira, 55.Araras, 76.Matão, 2.Jundiaí, 14.Indaiatuba, 9.Piracicaba.

9/10: 8.Campinas, 11.Tietê, 28.S.João da Boa Vista, 33.Ribeirão Preto, 42.Orlândia, 48.Araraquara, 1.Itu, 59.Porto Ferreira, 64.Jaú, 68.Bariri, 
79.Catanduva, 83.Bauru, 95.Marília, 112.Ourinhos, 114.Presidente Prudente, 81.Mirassol, 51.São Carlos, 22.Franca, 26.Amparo, 90.Birigui, 77.Barra Bonita, 3.Sorocaba, 50.Rio Claro.

10/10: 24.Batatais, 31.Cajuru, 41.Cravinhos, 43.S.Joaquim da Barra, 56.Barretos, 61.Guaíra

62.Itirapina, 63.Brotas, 67.Ibitinga, 85.Penápolis, 86.Pirajuí, 89.Araçatuba, 94.Garça, 105.São Manoel, 110.Assis, 111.Cerqueira César, 102.Santa Cruz do Rio Pardo, 53.Pirassununga, 104.Piraju, 57.Santa Rita, 117.Presidente Venceslau, 124.Itararé, 99.Botucatu, 97.Tupã, 101.Avaré, 32.Socorro, 87.Lins.

Apêndice A. 3 Mapeamento - 1980, segundo todos os fatores, utilizando rotação Varimax.

1/10: 27.Itapira.

2/10: 11.Tietê, 22.Franca, 29.Serra Negra, 67.Ibitinga.

3/10: 9.Piracicaba, 17.Salto, 20.Americana, 37.Mogi Guaçu, 40.Sertãozinho, 42.Orlândia, 49.Limeira, 76.Matão, 77.Barra Bonita, 2.Jundiaí, 18.Rio das Pedras, 14.Indaiatuba, 31.São Carlos, 35.Araras, 1.Itu, 15.Santa Bárbara, 26.Amparo.

4/10: 33.Ribeirão Preto, 39.São José R.Preto, 68.Bariri, 112.Ourinhos, 79.Catanduva, 114.Pres.Prudente, 28.S.João da B.Vista.

5/10: 25.Casa Branca, 65.Dois Córregos, 72.Taquaritinga, 73.Nova Europa, 75.Boa Esperança, 82.Pindorama, 93.Cafelândia, 113.Palmital, 118.Regente Feijó, 61.Guairá, 60.Monte Azul.

6/10: 6.Porto Feliz, 7.Bragança, 19.Laranjal, 30.São Simão, 31.Cajuru, 32.Socorro, 124.Itararé, 97.Tupã, 80.Novo Horizonte, 66.Ribeirão Bonito, 102.S.Cruz R.Pardo, 85.Penápolis, 105.São Manoel, 41.Cravinhos, 63.Brotas, 69.Itápolis, 70.Bocaina, 74.Dourados, 92.Avanhandava, 96.Andradina, 78.Sta. Adélia, 5.Itapetininga, 86.Pirajuí, 4.Atibaia, 34.Mococa, 101.Avaré, 104.Piraju, 110.Assis, 111.Cerqueira, 116.Cândido Mota, 117.Pres. Venceslau, 43.São Joaquim.

7/10: 45.Serra Azul.

8/10: 84.Piratininga, 88.Avaí, 94.Garça, 98.Pereira Barreto, 109.Salto Grande, 115.Chavantes, 119.Itapeva, 36.Patrocínio, 57.Santa Rita, 107.S.Pedro do Turvo, 120. Capão Bonito, 126. Apiaí, 122.Iporanga, 123.S.Miguel Arcanjo, 125.Ribeira, 103.Bofete, 13.Cabreúva, 106.Itatinga.

9/10: 10.São Roque, 24.Batatais, 48.Araraquara, 52.Descalvado, 53.Pirassununga, 54.Jaboticabal, 56.Barretos, 62.Itirapina, 71.Pederneiras, 81.Mirassol, 83.Bauru, 87.Lins, 89.Araçatuba, 90.Birigui, 95.Marília, 99.Botucatu, 108.Agudos, 8.Campinas, 50.Rio Claro, 3.Sorocaba, 64.Jaú, 21.Mogi Mirim, 91.Promissão, 100.Lençóis, 58.Bebedouro.

10/10: 23.Águas de Lindóia, 35.Igarapava, 38.Ituverava, 44.Morro Agudo, 46.Águas da Prata, 47.Pontal, 16.São Pedro 59.Porto Ferreira,12.Piracaia

\section{Dados dos autores}

Nome completo: Marly Cavalcanti

Filiação institucional: Centro Paula Souza

Departamento: Engenharia da Produção

Função ou cargo ocupado: Professora

Endereço: Av. Brigadeiro Luiz Antonio 1930 apt 111, Bela Vista, São Paulo, SP, Brasil, 01318-002

Telefones para contato: (11) 3288-0497 / (11)6145-4002

e-mail: cavalcanti.marly@gmail.com 
Nome completo: Osvaldo Elias Farah

Filiação institucional: Universidade Nove de Julho

Departamento: Pós-Graduação em Administração

Função ou cargo ocupado: Professor

Endereço: AV. Francisco Matarazzo 1900, São Paulo, SP, Brasil,

Telefones para contato: (11) 3284-3139

e-mail: oefarah@gmail.com

Recebido para publicação em: 01/02/2008

Aceito para publicação em: 28/02/2008 